\title{
Neurología: encefalitis letárgica en Despertares (1990)
}

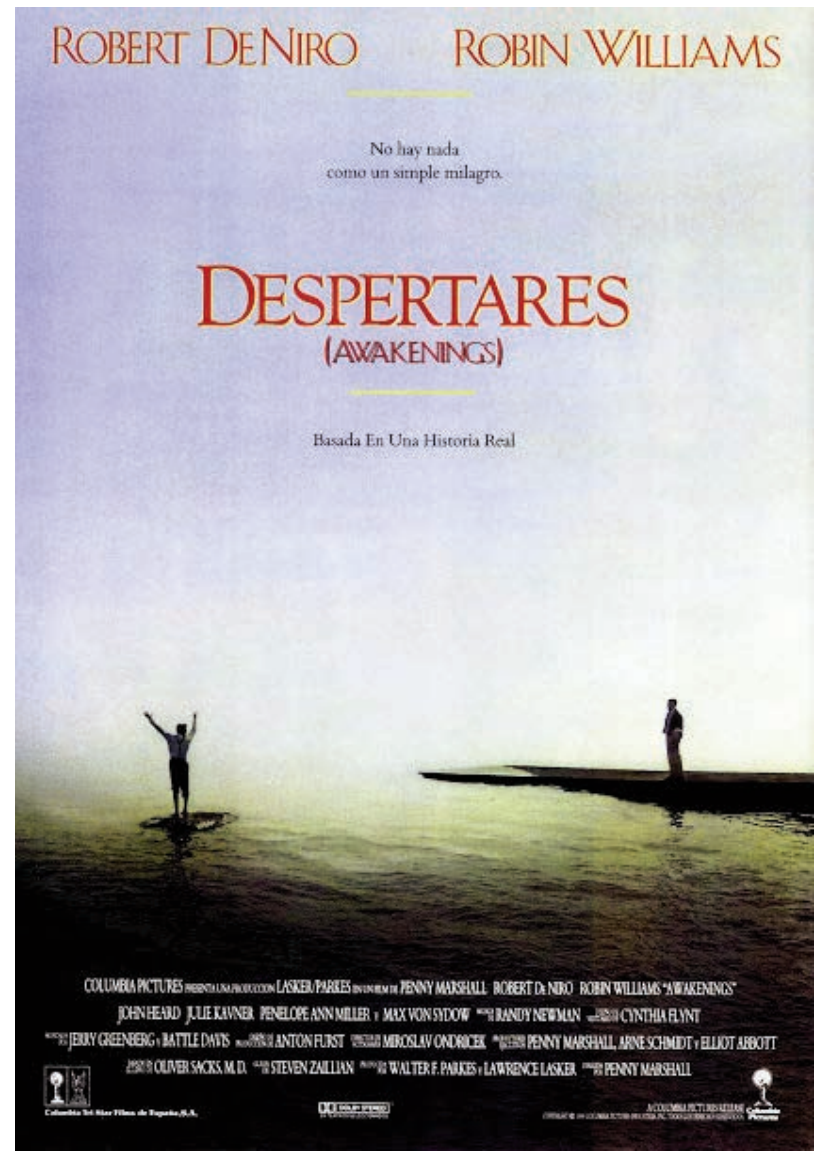

Acción: Nueva York. Años 20 del siglo pasado. Cartel español.

\section{Ficha técnica}

Título original: Awakenings.

País: Estados Unidos.

Año: 1990.

Director: Penny Marshall.

Música: Randy Newman.

Fotografía: Miroslav Ondrícek.

Montaje: Battle Davis, Gerald B. Greenberg.

Guión: Steve Zaillian. Adaptación del libro homónimo del Dr. Oliver Sacks. Basado en hechos reales.

Intérpretes: Robert de Niro, Robin Williams, Penelope Ann Miller, Julie Kavner, Ruth Nelson, John Heard, Alice Drummond, Judith Malina, Barton Heyman, George Martin, Anne Meara, Richard Libertini, Laura Esterman, Dexter Gordon, Jayne Haynes,...

Color: color.

Duración: 121 minutos.

Género: drama, melodrama.

Idioma original: inglés.

Productora: Columbia Pictures Corporation.

Sinopsis: la extraordinaria historia de un grupo de pacientes ingresados en el Hospital Monte Carmelo de Nueva York, sobrevivientes de la epidemia de encefalitis letárgica de los años 20 han quedado reducidas progresivamente a un estado vegetativo-parkinsoniano en un centro de enfermos crónicos. Años después, en 1969, el recién llegado Dr. Sayer (Robin Williams) se perturba ante esta situación. Muchos son catatónicos desde hace décadas y no tienen esperanza de cura. Investiga para dar con alguna solución y encuentra una posible solución química y prueba con uno de ellos, Leonard Lowe (Robert de Niro) un nuevo fármaco -la L-dopa- y genera el asombroso "despertar» que experimenta a los cuarenta años. Se deleita con la toma de conciencia de los pacientes y de las reacciones de sus familiares al reciente despertar, la esperanza y la emoción de revivir a sus seres queridos.

Premios: Nominada a los Oscar 1990 como mejor película, Mejor actor principal (Robert de Niro) y Mejor guión adaptado. Ganadora del Scriptor Award 1991.

Comentario explicativo: Leonard Lowe tenía 11 años cuando se sumió en el letargo misterioso y durmió durante 30 años hasta que el Dr. Sayer inicio el tratamiento con un fármaco llamado L-dopa.

Enlaces: https://www.imdb.com/title/tt0099077

$\underline{\text { Trailer }}$ 


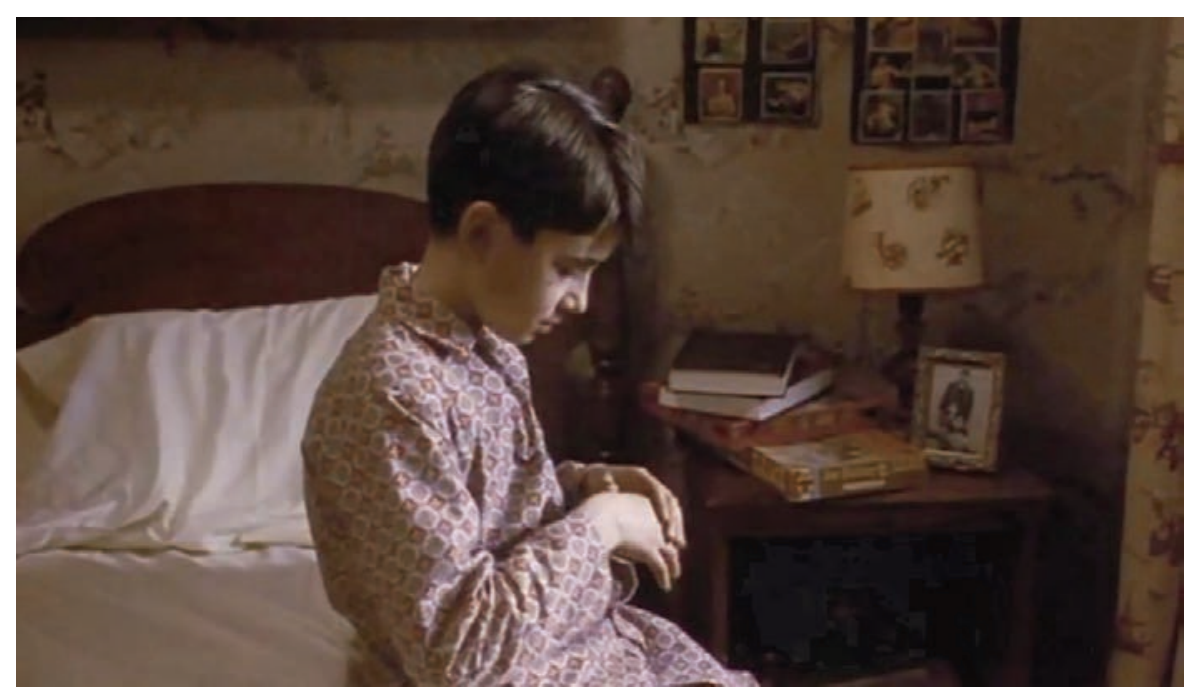

El Inicio abrupto de la enfermedad: temblor en las manos.

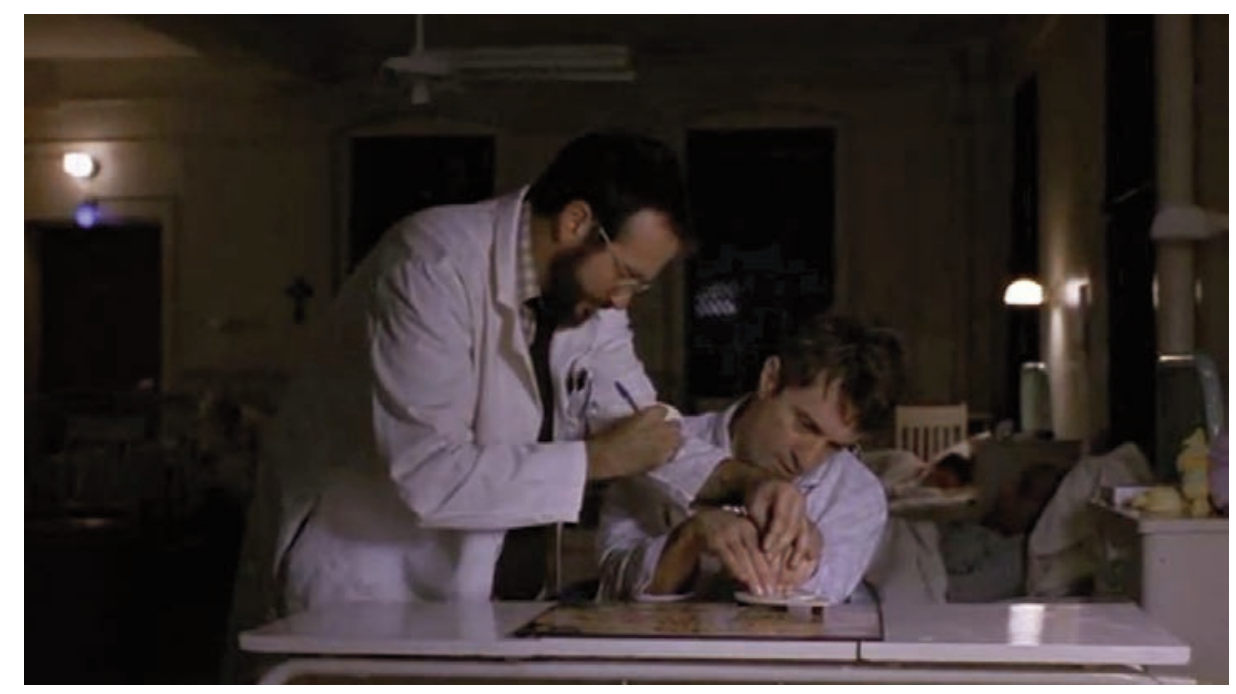

La enfermedad en su estado crónico, paciente en estado catatónico pero que presenta ligero movimientos. 


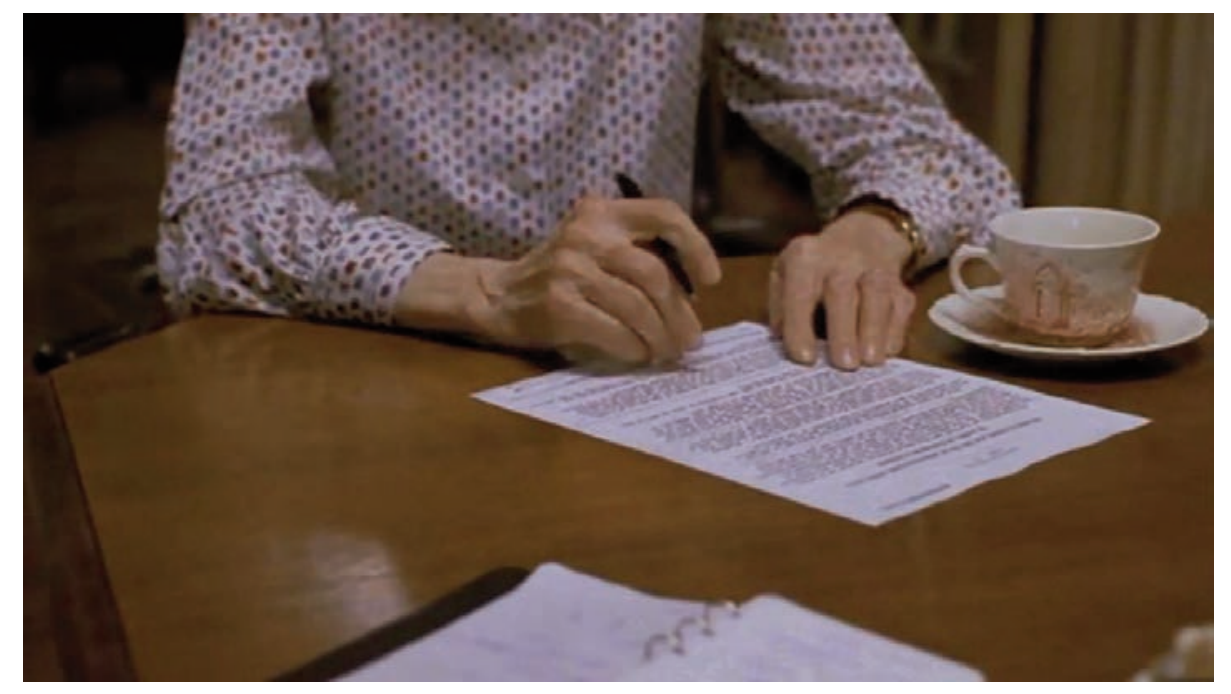

La madre de Leonard acepta el tratamiento con un nuevo fármaco que es L-dopa.

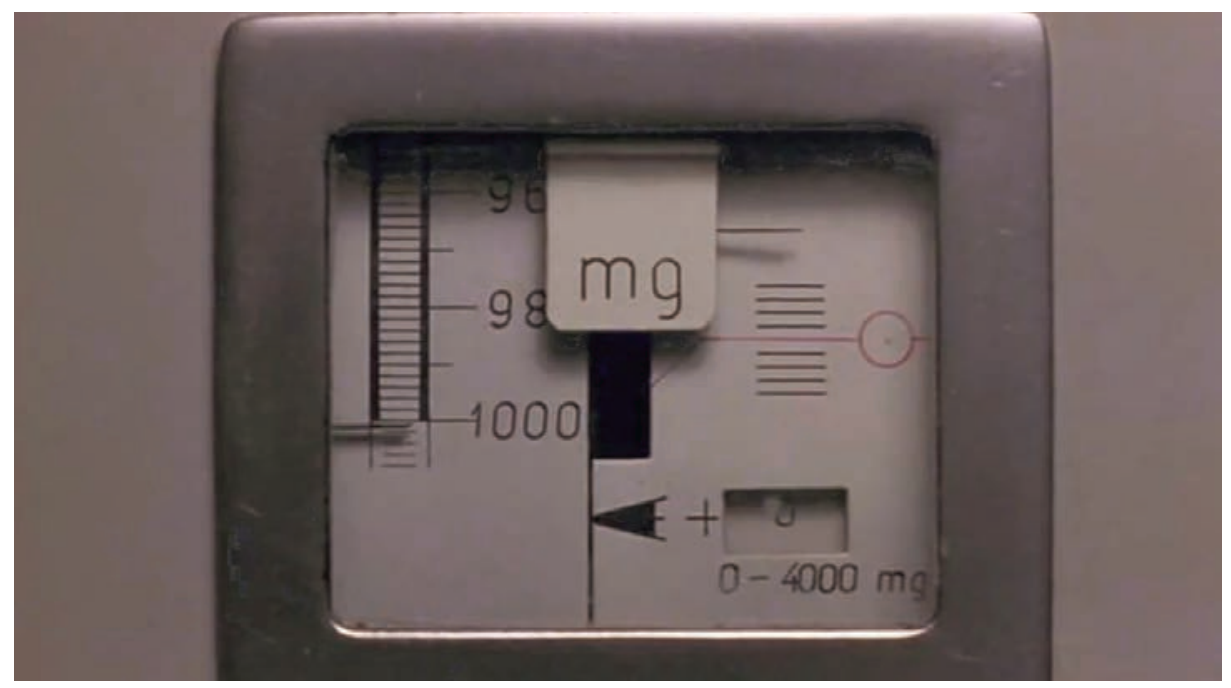

Dosificación del I-dopa. 


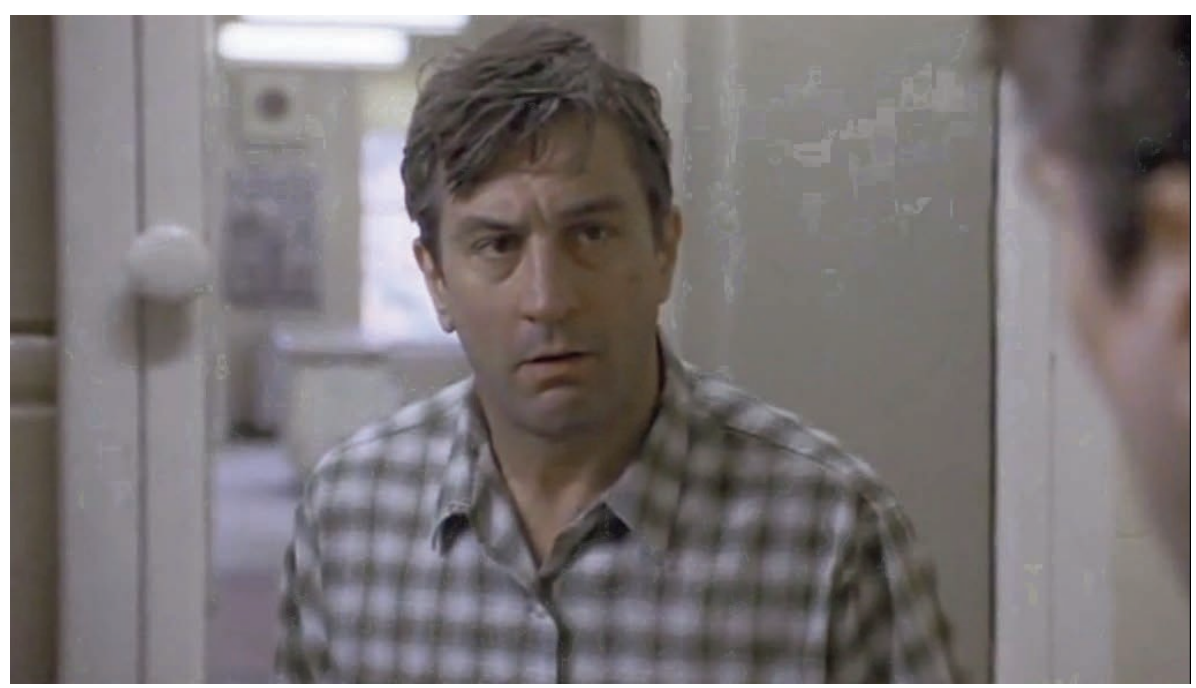

Despertar y sentirse desubicado como si su despertar en realidad fuera el despertar de su pensamiento.

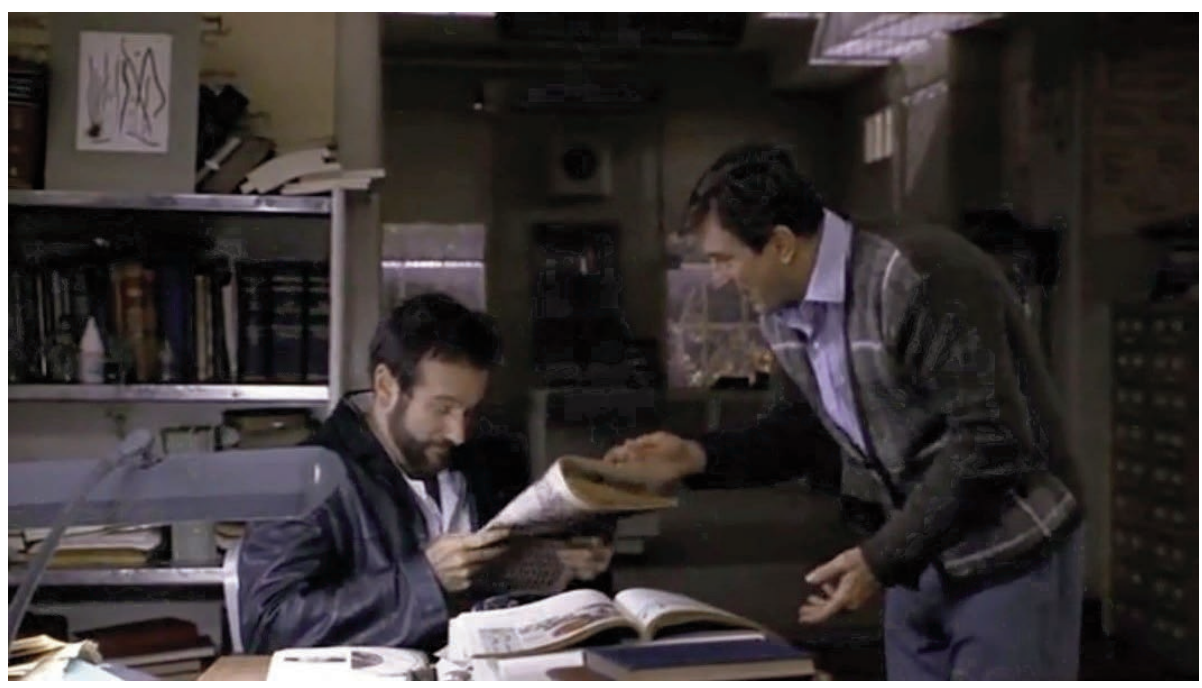

Paciente en tratamiento, presente control del sueño, aprendizaje significativo, procesos cognitivos y coordinación de los movimientos. 


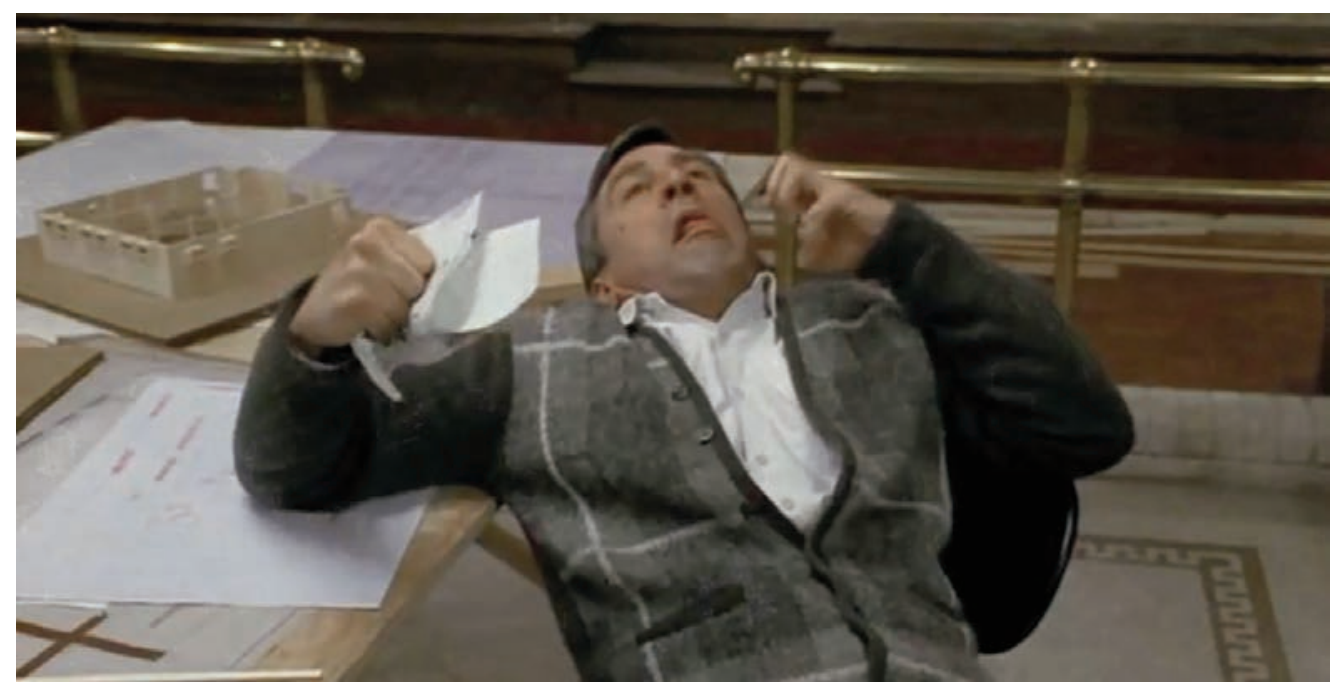

Recaída de la enfermedad, presenta temblor postural, crisis oculogiricas y movimientos extrapiramidales.

\section{Agradecimientos}

A la universidad Privada Norbert Wiener, a la Facultad de Medicina Humana, a mis profesores en especial a los doctores: Hans Lenin Contreras Pulache y José Rafael Díaz Rudas, quienes nos motivaron a ver películas realizando un análisis crítico y un enfoque médico, gracias a cada uno de ustedes por su paciencia, dedicación, apoyo incondicional.

\section{Karla ROJAS CESPEDES, Bertha BONILLA RAMÍREZ, Yanira BRIONES CALDERÓN, Virginia FLORES LANADAURO}

Facultad de Medicina Humana. Universidad Norbert Wiener (Perú).

Autor para correspondencia: Karla Rojas Cespedes. Correo electrónico: karlameryr@gmail.com

Como citar este artículo: Rojas Cespedes K, Bonilla Ramírez B, Briones Calderón Y, Flores Lanadauro V. Neurología: encefalitis letárgica en Despertares (1990). Rev Med Cine [Internet] 2019;15(3): 185-189.

DOI: http://dx.doi.org/10.14201/rmc2019153185189 